\title{
Professional competency based analysis of continuing tensions between education and training in higher education
}

\begin{abstract}
Purpose- The education and training of construction graduates are highly influenced by the higher education institutions which produced them and the relevant professional bodies, which set the competencies that guide both academic and industrial learning. Thus, it is important to ascertain what the key stakeholders perceive construction graduates should achieve in competencies. Construction is a practice-oriented collection of professions, thus, this research focused on the Quantity Surveying (QS) profession that is responsible for cost control and management of construction projects, and accredited by the Royal Institution of Chartered Surveyors (RICS). The purpose of this research is to identify and analyse the expected level of competencies attained by QS graduates, assess the industry perception of the achievement of competencies by QS graduates, and the ranking of competencies in the order of perceived importance.
\end{abstract}

Design/methodology/approach- The study adopted three different data gathering phases to include literature review, expert forum, and two surveys- industry and academia.

Findings- The research revealed unrealistically high expectations by the construction industry of QS graduates achieving a high level of competency in 10 mandatory, 7 core, and 7 optional competencies. The research found that there were significant levels of dissatisfaction with the expected level of achievement of mandatory, core and optional competencies by the QS graduates. Thus, a perception gap was identified between the academia and the industry.

Practical implication- This research will provide a benchmarking tool for curricula alignment for the construction degree programmes in higher education.

Originality/value- The identification of the exact nature of industry competencies requirements and any variations will assist the construction graduates to connect more effectively to the industry. These research findings confirm the need for continued expansion of curricula and diversification of pedagogies.

Keywords: Competencies, construction graduates, higher education, training, stakeholder

\section{Paper type Research paper}

\section{Introduction}

Studies on quality in Higher Education Institutions (HEIs) have received significant attention in the last decade. However, questions remain as to how well HEIs prepare graduates to meet the challenges of constantly evolving and demanding work environments (Holmes, 2001; Hills et al., 2003; Rubin and Dierdorff, 2009). Concerns remain that undergraduate programmes may not be equipping graduates with the key skills needed to gain and maintain employment (Binks, 1996; De La Harpe et al., 2000; Cranmer, 2006; Holmes, 2015). For instance, Maharasoa and Hay (2001) asserted that there is an international concern about the relationship between higher education, employability and the place of work. Mason et al. (2003) and Wilton (2008) claimed that the perceived lack of graduate employability appears rooted in the degree of mismatch between skills acquired in higher education versus those required for employment. This is corroborated by a number of studies in different disciplines. 
For instance, Azevedo et al. (2012) found that employers were not very confident in the level of capability of business graduates in the eight competencies investigated in their study. In engineering education, Male (2010) found gaps between the competencies required for engineering work and those developed in engineering education. Peng et al. (2016) found a mismatch between the educational attainment of a graduate with a Master of Engineering (MEng) degree and the industry needs in China. It is against this backdrop that Nilsson (2010) averred that the role of higher education in the construction and development of the employability of the future workforce has been the subject of debate. This is affirmed by Holmes (2013) that graduate employability has become, and is likely to continue to be, a major issue for a variety of stakeholders in HEIs. Against this backdrop, several studies have been conducted in enhancing the employability of graduates, their preparedness for labour market transition, and the role higher education has in preparing students (see Ropes, 2015; Monteiro et al., 2016, Thang and Wongsurawat, 2016) to mention a few.

Thus, HEIs need to identify different working patterns that graduates might engage in and ensure that they possess employability skills that employers prefer them to possess (Wickramasinghe and Perera, 2010). Ropes (2015) opined that HEIs should develop curricula in collaboration with industry, in order to prepare graduates with competencies that will help them to function effectively in changing work environments. This backdrop necessitated many professional bodies nationally and internationally to develop both the policy and standards for regulating various undergraduate programmes in HEIs. For example, in 2001, the Accreditation Board for Engineering and Technology (ABET), the sole agency responsible for accrediting engineering degrees in the United States, specified 11 competencies for their engineering graduates to demonstrate (ABET, 2008; ABET, 2014). Also, in the United States, American Council for Construction Education (ACCE) defines the standards and criteria by which those construction education programmes seeking accreditation or re-accreditation shall be assessed (ACCE, 2015). Similarly, in the UK, the Royal Institution of Chartered Surveyors (RICS)-the accrediting body for Quantity Surveying and Construction programmes, specified 24 competencies, which are grouped into 10 mandatory competencies, 7 core competencies, and 7 optional competencies, when setting its requirements for those seeking membership (RICS, 2009). Further, in the case of their graduate entrants, these competencies will have been acquired both through their formal university education and the workplace training which they have received, whether as parttime students in employment or during a work placement. Also, the Accreditation Council for Graduate Medical Education identified 6 general competencies in their accreditation criteria (Batalden et al., 2002) among others. Given this, construction, engineering, medical and other professionally-oriented programmes have begun to align their curricula with the outcomes stipulated by their respective criteria (see Batalden et al., 2002; Lattuca et al., 2006).

Therefore, there is an increasing evidence for the need for information about graduates' transition to work shortly after graduation, and graduates' early careers. It is on this premise that this research becomes necessary to ascertain what the key stakeholders' perceived construction graduates, particularly Quantity Surveying (QS) graduates, should achieve in competencies. In this respect, this research was guided by the following derived objectives:

- Empirically investigate the expected level of achievement of competencies by QS graduates.

- Assess the industry perception of the achievement of competencies by QS graduates

- Ranking of competencies in the order of perceived importance.

It is believed that this research will provide a benchmarking tool for curricula alignment for the construction degree programmes in HEIs. Also, the identification of the exact nature 
of industry competencies requirements and any variations will assist the construction graduates to connect more effectively to the industry.

\section{Competence-based education}

Studies have shown that no greater impulse for learning exists than assessment (see Frederiksen, 1984), thus, a call is growing for the development of assessment methods that can adequately determine competence acquisition (Baartman et al., 2007). For instance, in the knowledge society, HEIs have an important role to play in professional development. Higher education providers have the awareness that design and delivery of study programmes have to comply with industry practice and professional body requirements. The influence of industry on curriculum development is increasingly significant (Mekenzie, 2010). Benner (1984) developed a five-stage professional development model such as novice, advanced beginner, competent, proficient and expert, which could be used as a competence framework for professional education programmes. Competence-based education (CBE) initially started in nursing education in the 1970s (Cowan et al., 2007). Over the last 40 years, CBE has been gaining popularity in many disciplines in formal and informal education and training all around the world. Professional accreditation bodies in the construction-oriented degrees have also been advocates of a competency-based approach (Newton, 2009). There are various definitions of competence (Miller, 1990; Eraut, 1994; Parry, 1996; Verma et al., 2006).

Commonly, competence is described as the combination of knowledge, skills, and attitudes necessary in certain job contexts or job situation (Eraut, 1994). Competence-based education should address knowledge, skills and attitudes in an integrated way since each of these separately is not sufficient for the desired competent professional behaviour (Taconis et al., 2004). Verma et al. (2006) stated that the benefits of CBE are to foster empowerment, accountability and performance evaluation. Evidently, CBE has been widely used in Higher Education. The competency-based curricula have an integral set-up in which the profession is central (Boyatzis et al., 1996). It aims to assist students in obtaining high qualified professional competencies and increase graduate employability. However, CBE in higher education is not perfect; there are some critics who claim that its diminished process inhibits deep understanding and knowledge capture. Barnett (1994) argued that CBE can lead to loosely designed curricula that undermine the quest for deep understanding. On the other hand, curriculum design has to reflect current industrial practice in a fast changing world.

\section{RICS QS competency requirements}

The role of QS has evolved over the years since its origins in the mid- $19^{\text {th }}$ century and more recently through a series of reviews under the auspices of the RICS. The RICS report published in 1971 defined the role of the QS in a succinct and clear manner (RICS, 1971). It sought to establish the profession as specialists in measurement and valuation of construction works. This was then followed by the report on the future role of the chartered QS in 1983 (RICS, 1983) which identified the skills and knowledge base of the QS while identifying the scope for expansion and diversification of services. A greater level of detail and definition to the role of the QS was brought about by the RICS report on "the core skills and knowledge base of the quantity surveyor" (RICS, 1992). These provided the basis for the development of the RICS QS competencies (RICS, 2009). Thus, the RICS (2009) defined the level of achievement of competencies required of the chartered quantity surveyor as follows:

1 Mandatory competencies: personal, interpersonal, professional practice and business skills common to all pathways [into membership] and compulsory for all candidates.

2 Core competencies: primary skills of the candidate's chosen [RICS] pathway 
3 Optional competencies: selected as an additional skill requirement for the candidate's chosen [RICS] pathway from a list of competencies relevant to that pathway. In most cases there is an element of choice, though driven, usually, by their employer's specialism.

Consequently, the RICS distinguishes between three possible levels of attainment in each of a range of competencies when setting its requirements of those seeking membership. Briefly, these are as follows:

- Level 1: Knowledge (theoretical knowledge)

- Level 2: Knowledge and practical experience (putting it into practice)

- Level 3: Knowledge, practical experience, and capacity to advise (explaining and advising).

There are 10 mandatory competencies, 7 core competencies and 7 optional competencies (two only of these last to be selected by the candidate). The RICS stipulates that an Assessment of Professional Competence (i.e. APC) candidate needs to achieve all mandatory competencies at Level 2 or above, all core competencies at Level 3 (except one not relevant to specialisation depending on employment in consulting or contracting practice which is at Level 2) and 2 optional competencies at Level 2 or above. However, there is no such definition for the level of achievement of competencies for the graduate quantity surveyor (Perera and Pearson, 2011). This has resulted in individuals and organisations interpreting levels of achievement of competencies in their own way. Therefore, the aforementioned RICS QS competencies were adopted for the graduate QS and analysed in the relation to the objectives of this research as follows:

1. Establish the expected level of achievement of competencies by graduate QS

2. Establish the perceived level of achievement of competencies by graduate QS

3. Ranking of competencies in the order of perceived importance

The analysis and presentation of the findings are guided by aforementioned objectives.

\section{Research methodology}

Previous studies conducted to identify important competencies for professionally-oriented graduates, most especially for engineering graduates, surveyed two or more key stakeholders to include the academic staff, industry or professionals with over 5 years industrial experience, human resource, line managers, programme directors in HEIs (see Meier et al., 2000; Bodmer et al., 2002; Spinks et al., 2006; Brumm et al., 2006; Male et al., 2011). Also, few studies adopted literature review and conceptualization (see Woollacott, 2009; Male, 2010). Thus, this research adopted a literature review, an expert forum, and two surveys, of industry and academia, culminating in data analysis and reporting. The key stages and process are detailed as follows:

\subsection{Review}

A detailed literature review was carried out to identify the RICS QS competencies and their interpretation.

\subsection{Expert forum}

This was conducted for the purpose of the identification of key issues related to academia, industry, and the RICS. A total of 10 interviews were carried out comprising 3 academics (programme leaders), 3 consultant quantity surveyors, 3 contractor quantity surveyors and one RICS official (member of the RICS Education and Qualification Standards). The views obtained from this forum informed the development of the academic and industry 
questionnaire surveys. Both surveys were first piloted among a small sample of volunteers representing industry and academia. The review of the feedback obtained through a discussion session led to the modification of the questionnaires.

\subsection{Survey of the academia}

The issues identified from the literature and expert forum formed the basis of the survey questionnaire. The academic survey is one of the two surveys conducted. A comprehensive survey consisting of 41 questions was carried out to ascertain the views of the quantity surveying academic community across academic institutions in the UK. According to the RICS, there are 26 universities conducting a total of 51 programmes (31 undergraduate and 20 postgraduate) producing RICS accredited quantity surveying graduates. A total of 106 academic staff from all 26 universities which conduct RICS accredited programmes were contacted and web-based survey requests were sent. The survey received 65 responses from which 20 were eliminated due to the incompleteness of responses leaving 45 sets of fully completed survey responses. The survey data analysis is presented using the 45 fully completed survey responses received. The survey achieved response rates of $61 \%$ overall and $42 \%$ fully completed.

\subsection{Survey of the industry}

The issues identified from the literature and expert forum formed the basis of the survey questionnaire. A comprehensive survey consisting 39 questions was carried out to ascertain the views of the quantity surveying industrial and professional community across firms in the UK. This included clients, consulting and contracting firms representing both the private and public sectors. According to the RICS, there are approximately 7000 Chartered Quantity Surveyors registered in the UK. The survey was posted to a sample of 2946 chartered surveyors with high levels of experience randomly selected from the RICS member database. A total of 615 responded from which 314 were eliminated due to the incompleteness of responses leaving 301 sets of fully completed survey responses. The survey data analysis is presented using the 301 fully completed survey responses received. The survey achieved a response rate of $21 \%$ overall responses and $10 \%$ fully completed survey response rates. This was expected as the survey method did not use prior permission for the survey request which was mainly on a voluntary basis. However, the data sample is quite adequate to carry out an analysis with over $99 \%$ confidence level as the population size is large (Bartlett et al., 2001).

\section{Results}

\subsection{Survey respondent profiles}

The survey respondents for both surveys (industry and academia) were exceptionally experienced in QS work, with over 90\% have more than 10 years professional experience (see Figure 1 and 2). No direct comparison could be made between the natures of the workloads of each group. The academics spent approximately $50 \%$ of their time engaged in teaching and assessment, followed by administration with $25 \%$ and research $15 \%$ (see Figure 3 for details). Similarly, $51.80 \%$ of the industry respondents were consultants that engaged in private practice. Others include contracting with $17 \%$, the public sector $15 \%$ (see Figure 4).

\footnotetext{
>>>>> Insert Figure $1>>>>>$

Figure 1: Respondent QS experience profile (Academia)

>>>>> Insert Figure $3>>>>>$

Figure 3: Respondent work profile (Academia)
}

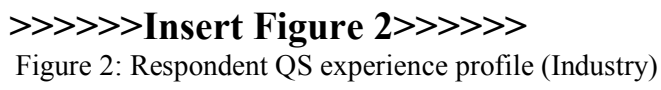




\subsection{Expected level of achievement of competencies by QS graduates}

It is important to ascertain what key stakeholders perceive a graduate should achieve in levels of competency. Thus, this section analyses the views of academics and industry to establish the expected level of achievement of competencies (i.e. mandatory, core and optional competencies) by QS graduates. Based on Level 1 to Level 3, where:

- Level 1: Knowledge (theoretical knowledge)

- Level 2: Knowledge and practical experience (putting it into practice)

- Level 3: Knowledge, practical experience, and capacity to advise (explaining and advising).

\subsubsection{Expected level for mandatory competencies}

Figure 5 and Table 1 reveal the academic responses on the 10 mandatory competencies. It indicates that the academic are expecting the highest level of experience to be at Level 2 with $46.44 \%$. For instance, the overall perception of academic on expected levels of mandatory competencies by QS graduates are $37.33 \%, 46.44 \%$, and $16.22 \%$ for level 1, level 2, and level 3 , respectively (see Figure 5 and Table 1 for details). Also, Figure 6 and Table 1 indicate the industry responses, it shows that the industry expecting the highest level of experience to be at Level 1 with $51.76 \%$. For example, the overall views of industry are $51.76 \%, 38.08 \%$, and $10.16 \%$ (see Figure 6 and Table 1 for details). In both cases, the highest ratings were given in the areas of M010 Team working, M004 Communication and negotiating, and M007 Data management It can be deduced that there was the difference in the perceptions of both the academic and industry on the expected level of mandatory competencies by QS graduates. However, both the academic and industry concurred on level 3 being the least level of experience expected of newly QS graduates.

>>>>>>Insert Figure 5>>>>>>

Figure 5: Expected Level of achievement of Mandatory Competencies for New graduate QS (Academic)
$>>>>>>>>$ Insert Figure $6>>>>>>>$

Figure 6: Expected Level of Achievement of Mandatory Competencies for New Graduate QS (Industry)

The final assessment of mandatory competencies was summarised in Table 1 as follows:

Table 1: Summary of expected levels for mandatory competencies

>>>>>>Insert Table 1 $>>>>>>$

Thus, it is recommended that mandatory competencies be achieved at level 1 and achieving level 2 at least in part for some competencies as indicated in Table 1.

\subsubsection{Expected level of core competencies}

Figures 7-8 and Table 2 indicate the perceptions of academic and industry on the expected levels of core competencies. It reveals that the overall perception of academic on expected levels of core competencies by QS graduates are $14.92 \%, 49.21 \%$, and $35.87 \%$ for level 1 , level 2, and level 3, respectively (see Figure 7 and Table 2 for details). In the same vein, the overall perception of industry on core competencies are $23.64 \%, 49.56 \%$, and $26.83 \%$ for level 1, level 2, and level 3, respectively (see Figure 8 and Table 2 for details). It can be seen from the finding that both the academic and industry unanimously agreed on the expectation of attainment at level 2 of core competencies for new QS graduates (see Table 2). Surprisingly, both the academic and industry were expecting a number of core competencies to be achieved at level 3 . For instance, the academic and industry expecting approximately $36 \%$ and $27 \%$ respectively of core competencies at level 3 (see Table 2 for details). Thus, 
expecting these percentages (i.e. $36 \%$ and $27 \%$ ) of core competencies at level 3 from new QS graduates indicate that both the academic and industry are exhibiting a wishful thinking. As new graduates are unlikely to be in a position immediately in advising clients, as the acquisition of Level 3 suggests (see RICS, 2009).

>>>>>>Insert Figure 7>>>>>>

Figure 7: Expected Level of achievement of Core

Competencies for New graduate QS (Academic)
>>>>>>>>> Insert Figure 8>>>>>>>

Figure 8: Expected Level of Achievement of Core Competencies for New Graduate QS (Industry)

The final assessment of core competencies was summarised in Table 2 as follows:

Table 2: Summary of expected levels for core competencies

>>>>> Insert Table 2 >>>>>

It is, therefore, recommended that core competencies be achieved at level 2 in part as indicated in Table 2. This is also justified by the fact that most programmes currently proceed to level 2 to some extent and have the full capacity to do so (see Table 2).

\subsubsection{Expected level for optional competencies}

Figures 9-10 and Table 3 reveal the perceptions of academic and industry on the expected levels of optional competencies. Thus, the overall perception of academic on expected levels of optional competencies by QS graduates are $52.38 \%, 36.51 \%$, and $11.11 \%$ for level 1 , level 2, and level 3, respectively (see Figure 9 and Table 3 for details). In the same vein, the overall perception of industry on expected levels of optional competencies are $69.81 \%, 24.67 \%$, and $5.51 \%$ (see Figure 10 and Table 3 for details). It can be seen that both the academic and industry agreed on the expectation of optional competencies for new QS graduates at level 1 (see Table 3 for details).

>>>>>>Insert Figure 9>>>>>>

Figure 9: Expected Level of achievement of Optional Competencies for New graduate QS (Academic)
>>>>>>> Insert Figure 10 $>>>>>>$

Figure 10: Expected Level of Achievement of Optional

Competencies for New Graduate QS (Industry)

The final assessment of optional competencies was summarised in Table 3 as follows:

Table 3: Summary of expected levels for optional competencies

>>>>>>Insert Table 3 >>>>>>

It is recommended that optional competencies be achieved at level 1 but a few number of optional competencies may be extended in part to level 2 as indicated in Table 3.

\subsection{Perceived level of achievement of competencies by QS graduates}

Figure 11 reveals the perception of the industry on the level of achievement of competencies comprising mandatory, core, and optional competencies by QS graduates. However, the perception of academics was not captured because they are actively involved in the development of graduates. Thus, Figure 11 indicates the graduate competency achievement in all the competencies with the mean score values ranging from 2.05 to 2.96 . This implies that the industry is partially satisfied with the competencies achieved by the graduates. Also, it can be seen that 10 out of 24 competencies have mean score values between 2.50 and 2.96. These 10 competencies comprised 6 mandatory and 4 core competencies. The 6 mandatory competencies are M007 Data management; M010 Team working; M009 Sustainability; 
M008 Health and safety; M005 Conduct rules, ethics and professional practice; and M004 Communication and negotiation. Similarly, the 4 core competencies include T022 Design economics and cost planning; T062 Procurement and tendering; T017 Contract practice; and T013 Construction technology and environmental services (see Figure 11 for details).

\section{>>>>>>Insert Figure 11 $>>>>>>$}

Figure 11: Industry's perception of achievement of competencies by QS graduates

\subsection{Ranking of competencies in the order of perceived importance}

Figure 12 reveals the perception of academics and industry on the level of importance of mandatory, core, and optional competencies in quantity surveying. Thus, Figure 12 is demarcated into three layers-the upper layer is mandatory competencies, the middle layer is core competencies, and the bottom layer is optional competencies. Therefore, the ranking of these competencies in term of importance by both academics and industry are as follows:

\subsubsection{Ranking of mandatory competencies}

As indicated in Figure 12, academics ranked M004 Communication and negotiation; M010 Team working; and M005 Conduct rules, ethics and professional practice above other mandatory competencies and awarded them the highest scores of 5, 5, and 4.5, respectively. In the same vein, industry ranked M003 Client care; M004 Communication and negotiation; M005 Conduct rules, ethics and professional practice; M006 Conflict avoidance, management, and dispute resolution procedures; and M010 Team working higher than others but with a maximum score of 4 (see Figure 12 for details). It can be seen that both academics and industry have a similar perspective on the relative status of mandatory competencies for the most part.

\subsubsection{Ranking of core competencies}

It can be seen from Figure 12 that academics ranked all core competencies equal to the highest rating of 5. Similarly, the industry ranked T062 Procurement and tendering; T067 Project financial control and reporting; and T074 Quantification and costing of construction works the highest with a score of 5 , while all other core competencies received a ranking of 4 (see Figure 12). This reflects a more pragmatic ranking considering the industry needs.

\subsubsection{Ranking of optional competencies}

As shown in Figure 12, academics ranked all optional competencies between 3 and 4. While industry ranked optional competencies ranging from 2 to 4 (see Figure 12 for details). Further, both the industry and academics ranked T016 Contract administration and T077 Risk management highest with a score of 4 . On the other hand, the least ranked optional competencies are T008 Capital allowances; and T020 Corporate recovery and insolvency with a score of 2 (see Figure 12 for details).

>>>>>>Insert Figure 12>>>>>>

Figure 12: Ranking of competencies in the order of perceived importance

\subsection{Cross comparison of levels of expectation, achievement and importance of competencies}

A cross comparison of industry perceptions on expected level of competence, the importance of competency, and level of achievement of competency by graduates is cross plotted to evaluate the relationship with these criteria (see Figure 13). Thus, expected level has been re- 
scaled to a 1 to 5 scale to graphically compared with an importance ranking (scaled 1 to 5) and perceived achievement (scaled 1 to 5) (see Figure 13 for details). From this comparison, it is clear that whilst there is high importance attached to a competence, there may be a comparatively lower level of achievement. This is established in this study. For example, the competencies that show wider gaps between expectation and achievement are listed as follows (see Figure 13):

1. M003 Client care

2. M004 Communication and negotiation

3. M006 Conflict avoidance, management and dispute resolution procedures

4. T010 Commercial management of construction

5. T062 Procurement and tendering

6. T067 Project financial control and reporting

7. T074 Quantification and costing of construction works

8. T016 Contract administration

9. T077 Risk management

These 9 (out of 24) competencies comprised 3 mandatory, 4 core and 2 optional competencies respectively, which have a significantly high importance in the role of the quantity surveyors (see Figure 13 for details).

\section{>>>>>>Insert Figure 13>>>>>>}

Figure 13: Cross comparison of competency expected level, importance ranking, and graduate achievement

\section{Discussion}

The role of higher education institutions (HEIs) in providing quality education and training systems that produce graduates that meet the current and future needs of the employers/industry and society at large was recognised. Thus, the purpose of this research was to identify and analyse the expected levels of competency attained by Quantity Surveying (QS) graduates; assess the industry's perception of the achievement of competencies by QS graduates, and rank competencies in the order of perceived importance. These research objectives were addressed from a multitude of angles; a literature review, the views of an expert forum, and two surveys- industry and academia. The expert forum consisted of 10 members representing private practice (consultants - 3), contracting (3), academia (3) and the professional body 'RICS' (1). The surveys were comprehensive with the academic survey receiving 45 completed responses from 26 universities producing RICS accredited quantity surveying graduates in the UK. The industry survey receiving 301 completed responses representing consultant, contractor, public sector and specialist quantity surveyors. This approach was similar to previous studies. For instance, Brumm et al. (2006) surveyed 212 stakeholders including employers, academic staff, and students when developing and assessing programme outcomes through workplace competencies for engineering students at Iowa State University, United States. Other similar studies that surveyed stakeholders when identifying generic competencies for engineering graduates (see Meier et al. 2000; Bodmer et al., 2002; Male et al., 2011).

This research revealed the 24 QS competencies classified as mandatory (10), core (7) and optional (7) (RICS 2009). These competencies can be achieved at any of three levels as Level 1, 2 or 3 (see RICS, 2009). The RICS QS competencies provide the basis on which the competence of a chartered quantity surveyor is defined. Thus, all the 24 RICS QS competencies were examined in the relation to the study's objectives. Adopting RICS QS 
competencies was similar to previous studies in construction oriented degree programmes. For instance, Newton and Goldsmith (2011) collated learning outcome statements for Quantity Surveying and Construction from the mandatory and core competencies of the RICS. These research findings revealed unrealistically high expectations by the industry of QS graduates achieving a high level of competency in 10 mandatory, 7 core, and 7 optional competencies. This is illustrated in Figure 14 as follows:

>>>>>>Insert Figure 14 >>>>>>

Figure 14: Perception gap in graduate competency

The views of both the industry and academia were logical to some extent on the expectations of level 1 achievement for the most mandatory competencies and level 2 for all the core competencies, and level 1 for the most optional competencies. However, there were some worrying trends with over 35\% expecting level 2 for mandatory competencies, level 3 for some core competencies and level 2 for some optional competencies. These far exceed the levels that can be practicably achieved by a new graduate. For example, a level 3 competency would require experience in advising clients and exhibiting expertise (RICS, 2009). These certainly cannot be achieved in a university (classroom) environment (see Figure 15 for details). The research findings further indicated that there were markedly low levels of ranking of the current state of achievement of competencies by new graduates. On a scale of 1 to 5, the overwhelming majority indicated the midpoint for most competencies and a score of 2 for others. The scoring was higher for mandatory competencies such as M010 Teamwork, M007 Data management, and M009 Sustainability. All core competencies were ranked much lower, the least satisfaction being shown with core competency T074 Quantification and costing of construction works, followed by T067 Project financial control and reporting. This finding was slightly similar to several studies that identified Teamwork as most important amongst the generic competencies for engineering graduates (see Meier et al., 2000; Bodmer et al., 2002; Brumm et al., 2006; Reio and Sutton, 2006; Male et al., 2011). This research concludes that there were significant levels of dissatisfaction with the expected level of achievement of mandatory, core and optional competencies by the QS graduates. Thus, perception gap was identified between the academia and the industry.

\section{Conclusions}

This research provided the empirical evidence on the competencies expected and attained by new graduates upon entry into an early career in the case of Quantity Surveying profession. In achieving this, several research instruments such as a review, an expert forum, academic and industry surveys were conducted. The results of the academic survey revealed that the academics expected the graduates would reach Level 2 of most mandatory competencies, Level 2 (or 3 in some cases) of core competencies and Level 1 or 2 of optional competencies. It can be deduced that these far exceed the levels that can be practicably achieved by a new graduate. For example, a Level 3 competency would require experience in advising clients and exhibiting expertise. These certainly cannot be achieved in a university (i.e. classroom) environment. The findings from the industry survey indicated that the competency level expectations of the industry were more pragmatic for the most part. However, there were significant levels of unrealistic expectations with over 35\% expecting Level 2 for mandatory competencies, Level 3 for some core competencies and Level 2 for some optional competencies. Also, the research revealed considerably low levels of ranking of the current state of achievement of competencies by new graduates. Based on these research findings, it is established that the current industry competence needs are not being adequately met by 
graduate competencies falling short of industry expectations. Thus, the HEIs have yet to respond effectively to the current and future challenges in addressing the 'mismatch' between the industry expectations and the competencies of graduates in construction-oriented programmes. This research, therefore, advocates greater levels of university and industry collaboration in developing and delivering construction programmes at large in HEIs.

\section{Acknowledgments}

The authors wish to acknowledge the RICS Research Trust, members of Construction Economics and Management Research Group (CEMRG) in the Faculty of Engineering and Environment, and Northumbria University for their support for this research.

\section{References}

Accreditation Board for Engineering and Technology (ABET) (1998), ABET 2000: criteria for accrediting programs in engineering in the United States, ABET, Baltimore.

Accreditation Board for Engineering and Technology (ABET) (2014), Criteria for accrediting engineering programs: effective for reviews during the 2015-2016 accreditation cycle, ABET, Baltimore.

American Council for Construction Education (ACCE) (2015), "Standards and criteria for accreditation of postsecondary construction education degree programs", available at: http://www.acce-hq.org/images/uploads/Doc 103 OBS final 042915.pdf (Accessed 8 December 2015).

Azevedo, A., Apfelthaler, G. and Hurst, D. (2012), "Competency development in business graduates: An industry-driven approach for examining the alignment of undergraduate business education with industry requirements", International Journal of Management Education, Vol. 10 No 1, pp. 12-28.

Baartman, L. K. J., Bastiaens, T. J., Kirschner, P. A. and Van der Vleuten, C. P. M. (2007), "Evaluation assessment quality in competence-based education: a qualitative comparison of two frameworks", Educational Research Review, Vol. 2 No 2, pp. 114-129.

Barnett, R. (1994) The limits of competence, Open University Press, Buckingham, UK.

Bartlett, J. E., Kottrlliikk, J. W. and Higgins, C. (2001), "Organizational research: determining appropriate sample size in survey research", Information Technology, and Learning, and Performance Journal, Vol. 19 No 1, pp. 43-50.

Batalden, P., Leach, D., Swing, S., Dreyfus, H. and Dreyfus, S. (2002), "General competencies and accreditation in graduate medical education", Health Affairs, Vol. 21 No.5, pp.103-111.

Benner P. (1984) From Novice to Expert, Addison-Wesley, New York.

Binks, M. (1996), "Enterprise in higher education and the graduate labour market", Education + Training, Vol. 38 No. 2, pp. 26-29.

Bodmer, C., Leu, A., Mira, L. and Rütter, H. (2002), "SPINE: successful practices in international engineering available at: http://www.ingch.ch/pdfs/spinereport.pdf (Accessed 24 December 2015).

Boyatzis, R., Leonard, D. C., Rhee, K. S. and Wheeler, J. V. (1996), "Competencies can be developed, but not in the way we thought", Capability, Vol. 2 No.2, pp. 25-41.

Brumm, T. J., Hanneman, L. F. and Mickelson, S. K. (2006), "Assessing and developing program outcomes through workplace competencies", International Journal of Engineering Education, Vol. 22 No.1, pp. 123-129. 
Cowan, D. T., Norman, I. and Coopamah, V. P. (2007), "Competence in nursing practice: a controversial concept - a focused review of literature", Accident and Emergency Nursing, Vol. 15 No 1, pp. 20-26.

Cranmer, S. (2006), "Enhancing graduate employability: best intentions and mixed outcomes", Studies in Higher Education, Vol. 31 No 2, pp. 169-184.

Dainty, A., Cheng M. I. and Moore, D. (2004), "A competency-based performance model for project managers”, Construction Management and Economics, Vol. 22 No 8, pp. 877889.

De La Harpe, B., Radloff, A. and Wyber, J. (2000), "Quality and generic professional skills", Quality in Higher Education, Vol. 6 No 3, pp. 231-243.

Eraut, M. (1994), Developing professional knowledge and competence, Routledge, London.

Frederiksen, N. (1984) "The real test bias. Influences of testing on teaching and learning", American Psychologist, Vol. 39 No 3, pp. 193-202.

Hills, J. M., Robertson, G., Walker, R., Adey, M. A. and Nixon, I. (2003), "Bridging the gap between degree programme curricula and employability through the implementation of work-related learning", Teaching in Higher Education, Vol. 8 No 2, pp. 211-231.

Holmes, L. (2001), "Reconsidering graduate employability: the graduate identity approach", Quality in Higher Education, Vol. 7 No 2, pp. 111-119.

Holmes, L. (2013), "Competing perspectives on graduate employability: possession, position or process?" Studies in Higher Education, Vol. 38 No 4, pp.538-554.

Holmes, L. (2015), "Becoming a graduate: the warranting of an emergent identity", Education + Training, Vol. 57 No.2, pp. 219-238.

Lattuca, L. R., Terenzini, P. T. and Volkwein, J. F. (2006), Engineering change: a study of the impact of EC2000, Final Report, ABET, Baltimore: ABET.

Maharasoa, M. and Hay, D. (2001), "Higher education and graduate employment in South Africa", Quality in Higher Education, Vol. 7 No 2, pp. 139-147.

Male, S. A. (2010), "Generic engineering competencies: a review and modelling approach" Education Research and Perspectives, Vol. 37 No 1, pp. 25-51.

Male, S. A., Bush, M. B. and Chapman, E. S. (2011), "An Australian study of generic competencies required by engineers", European Journal of Engineering Education, Vol. 36 No 2, pp. 151-163.

Mason, G., Williams, G., Cranmer, S. and Guile, D. (2003), How much does higher education enhance the employability of graduates? Higher Education Funding Council for England, Bristol.

Meier, R. L., Williams, M. R. and Humphreys, M. A. (2000), "Refocusing our efforts: assessing non-technical competency gaps", Journal of Engineering Education, Vol. 89 No.3, pp. 377-385.

Mekenzie, F. (2010), "Embrace this high level of industry engagement - it can benefit us all, the higher education", available at:

http://www.timeshighereducation.co.uk/story.asp?storyCode $=\&$ sectioncode $=26$

(Accessed 4 December 2015).

Miller, G. E. (1990), "The assessment of clinical skills/competence /performance”, Academic Medicine, Vol. 65 No 9, pp. 63-67.

Monteiro, S., Almeida, L. and Aracil, A. G. (2016), "Graduates' perceptions of competencies and preparation for labour market transition: the effect of gender and work experience during higher education", Higher Education, Skills and Work-Based Learning, Vol. 6 No. 2, pp. 208-220.

Newton, S. (2009), "Transformational higher education in the built environment" Journal for Education in the Built Environment, Vol. 4 No 1, pp. 100-112. 
Newton, S. and Goldsmith, R. (2011), "An analysis of stakeholder preferences for threshold learning outcomes in construction management in Australia", In Egbu, C. and Lou, E.C.W. (Eds.) Proceedings $27^{\text {th }}$ Annual ARCOM Conference, 5-7 September, Bristol, UK.

Nilsson, S. (2010), "Enhancing individual employability: the perspective of engineering graduates", Education + Training, Vol. 52 No. 6/7, pp. 540-551.

Parry, S. B. (1996), "The quest for competencies: competence studies can help you make HR decisions, but the results are only as good as the study", Training, Vol. 33, pp. 48-56.

Peng, L., Zhang, S. and Gu, J. (2016), "Evaluating the competency mismatch between Master of Engineering graduates and industry needs in China", Studies in Higher Education, Vol. 41 No 3, pp. 445-461.

Perera, S. and Pearson, J. (2013), "RICS professional competency mapping framework for programme appraisal and benchmarking, RICS Research Trust funded research Main Report RICS”, available at: http://www.rics.org/uk/knowledge/research/researchreports/professional-competency-mapping-framework/ (Accessed 20 September 2014).

Reio, T. G. and Sutton, F. C. (2006), "Employer assessment of work-related competencies and workplace adaptation", Human Resource Development Quarterly, Vol. 17 No 3, pp. 305-324.

RICS (1971), The future role of the quantity surveyor, RICS, UK.

RICS (1983), The future role of the chartered quantity surveyor, RICS, UK.

RICS (1992), The core skills and knowledge base of quantity surveyors, RICS, UK.

RICS (2009), "Requirements and competencies: RICS education and qualification standards", available at: http://www.rics.org/site/scripts/download info.aspx?fileID $=3729 \&$ categoryID $=98$ ( Accessed 20 September 2014).

Ropes, D. (2015), "Management competencies anno 2025: consequences for higher education", Higher Education, Skills and Work-Based Learning, Vol. 5 No.3, pp. 258 -270 .

Rubin, R. S. and Dierdorff, E. C. (2009), "How relevant is the MBA? Assessing the alignment of required curricula and required managerial competencies", Academy of Management Learning and Education, Vol. 8 No 2, pp.208-224.

Spinks, N., Silburn, N. and Birchall, D. (2006), "Educating engineers for the 21 st century: the industry view", available at: http://www.raeng.org.uk/publications/reports/educatingengineers-for-the-21st-century (Accessed 24 December 2015).

Taconis, R., Van der Plas, P. and Van der Sanden, J. (2004), "The development of professional competencies by educational assistants in school-based teacher education", European Journal of Teacher Education, Vol. 27 No 2, pp.215-240.

Thang, P. V. M. and Wongsurawat (2016), "Enhancing the employability of IT graduates in Vietnam”, Higher Education, Skills and Work-Based Learning, Vol. 6 No. 2, pp.146161.

Verma, S., Paterson, M. and Medves, J. (2006), "Core competencies for health care professionals: what medicine, nursing, occupational therapy, and physiotherapy share", Journal of Allied Health, Vol. 35 No 2, pp.109-116.

Wickramasinghe, V. and Perera, L. (2010), “Graduates', university lecturers' and employers' perceptions towards employability skills", Education + Training, Vol. 52 No.3, pp. $226-244$

Wilton, N. (2008), "Business graduates and management jobs: an employability match made in heaven? Journal of Education and Work, Vol. 21, pp. 143-158. 
Woollacott, L. C. (2009), "Validating the CDIO syllabus for engineering education using the taxonomy of engineering competencies", European Journal of Engineering Education, Vol. 34 No 6, pp.545-559. 


\section{List of Figures}
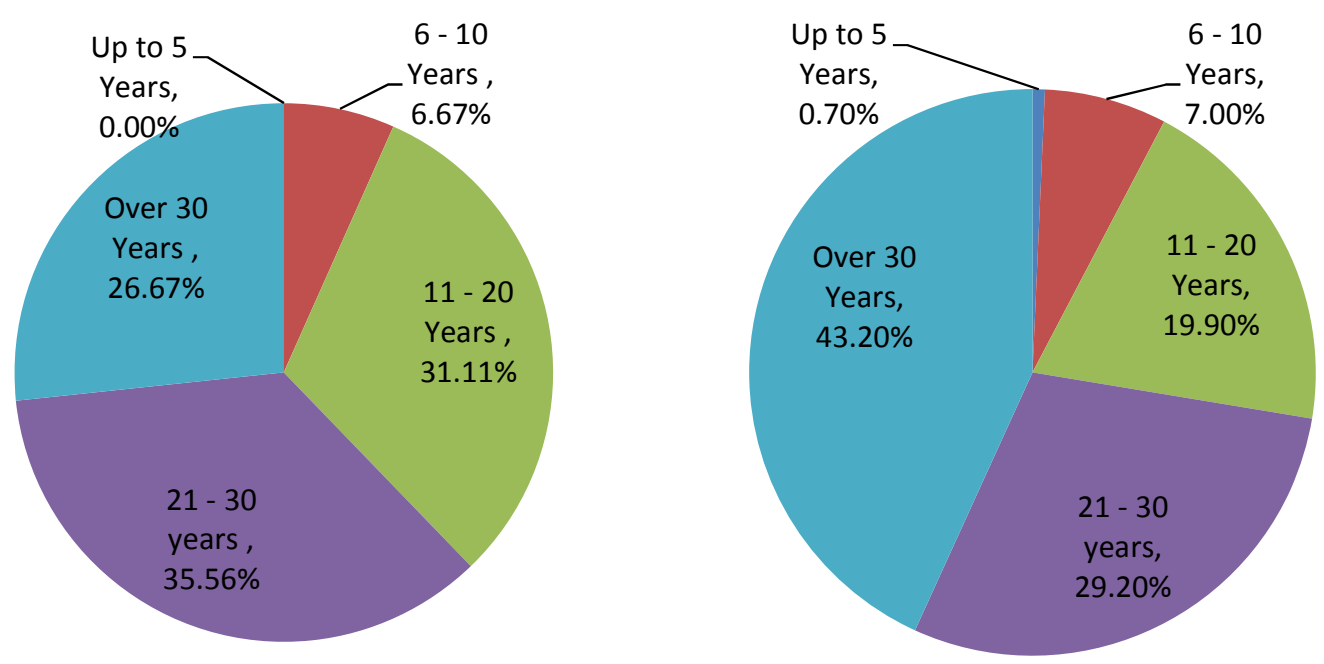

Figure 1: Respondent QS experience profile [Academia]

Figure 2: Respondent QS experience profile [Industry]
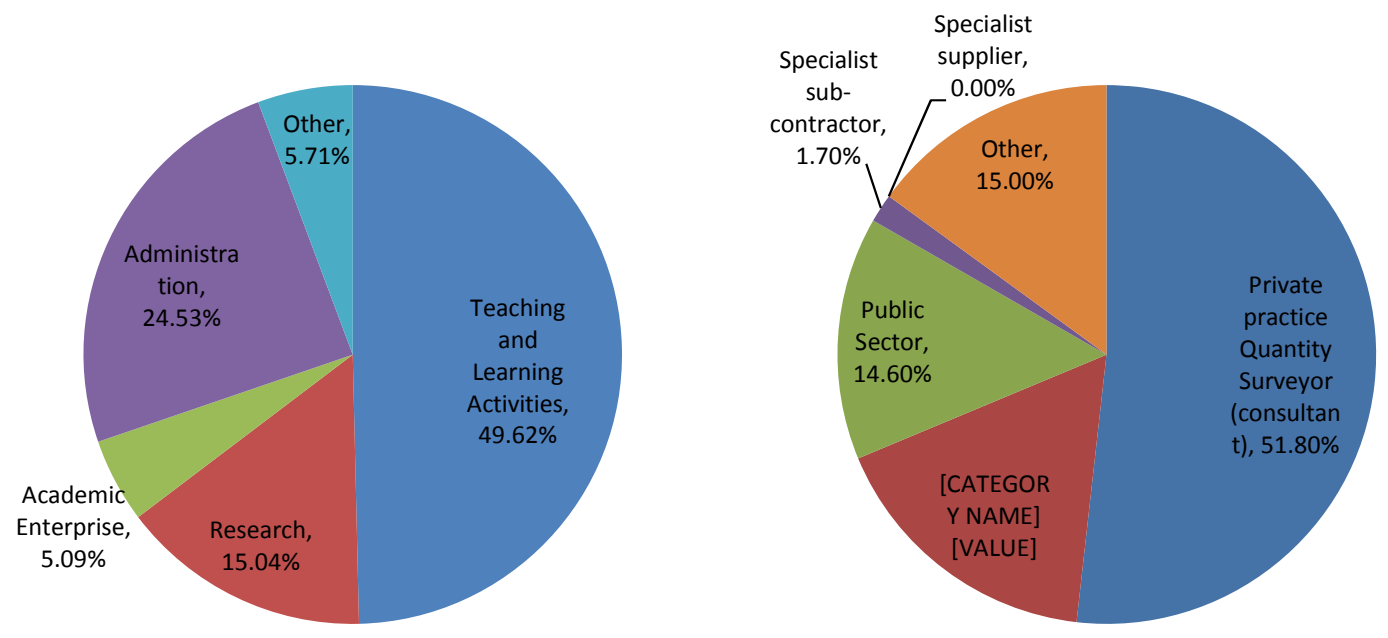

Figure 3: Respondent work profile [Academia]

Figure 4: Respondent work profile [Industry] 


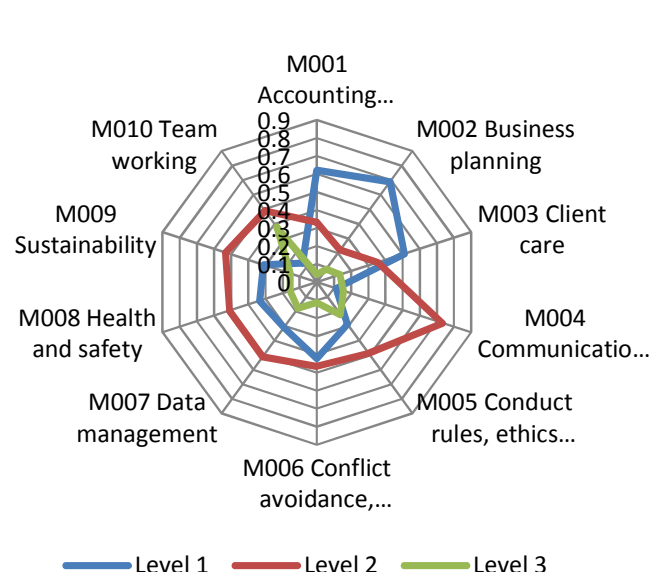

Figure 5: Expected Level of achievement of Mandatory Competencies for New graduate QS (Academic)

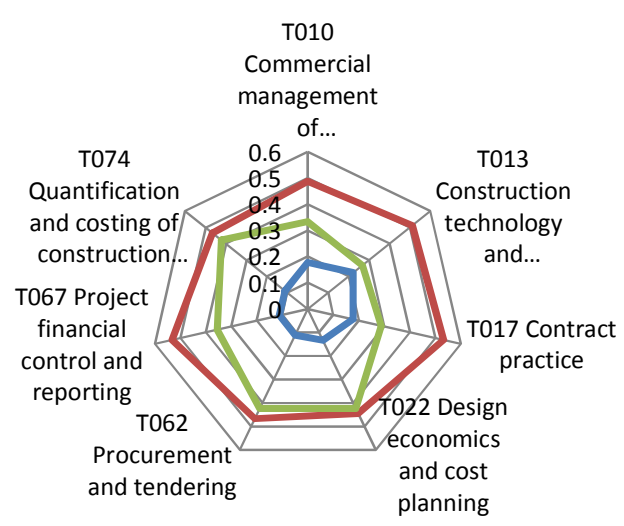

Level $1 \longrightarrow$ Level $2 \longrightarrow$ Level 3

Figure 7: Expected Level of achievement of Core Competencies for New graduate QS [Academic]

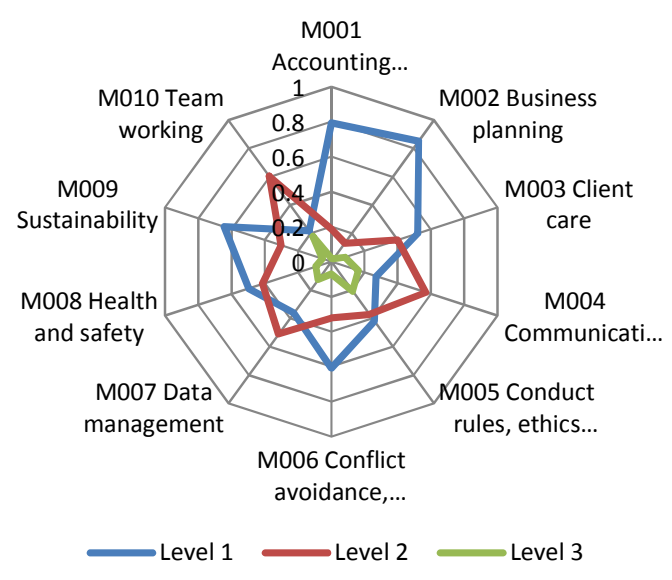

Figure 6: Expected Level of Achievement of Mandatory Competencies for New Graduate QS (Industry)

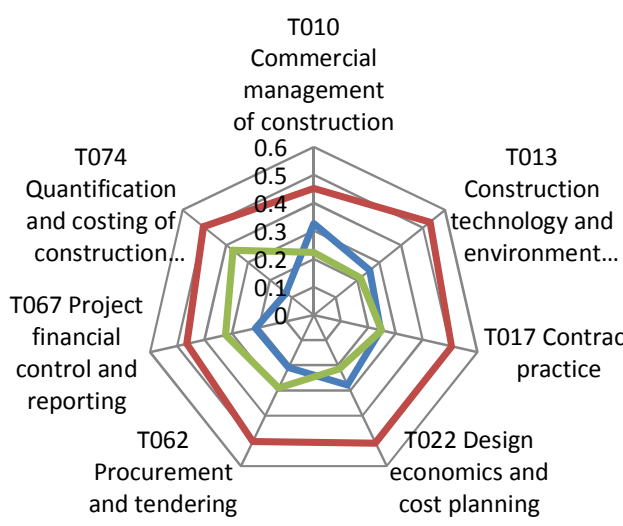

$\longrightarrow$ Level $1 \longrightarrow$ Level $2 \longrightarrow$ Level 3

Figure 8: Expected Level of Achievement of Core Competencies for New Graduate QS [Industry] 


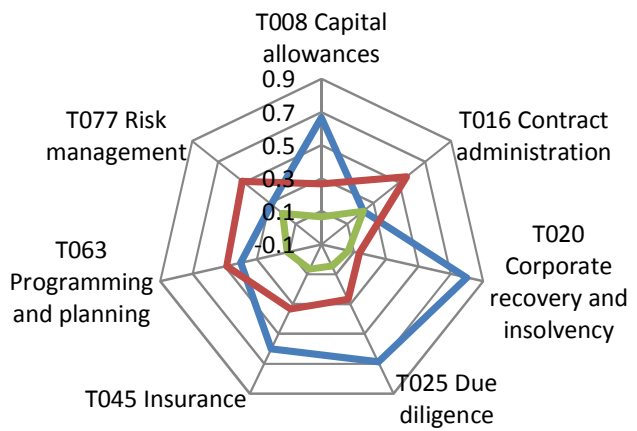

$\longrightarrow$ Level $1 \longrightarrow$ Level $2 \longrightarrow$ Level 3

Figure 9: Expected Level of achievement of Optional Competencies for New graduate QS (Academic)

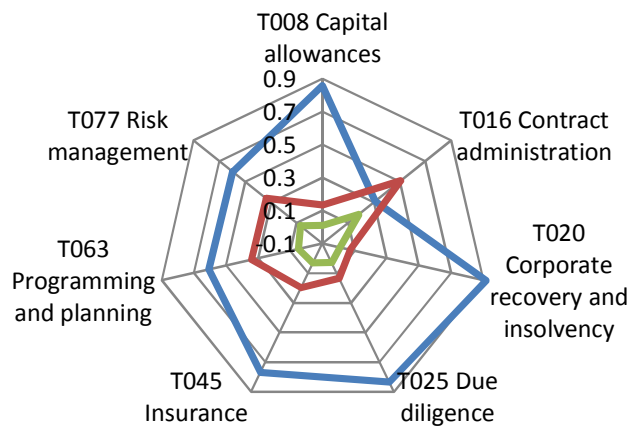
Competencies for New Graduate QS (Industry)

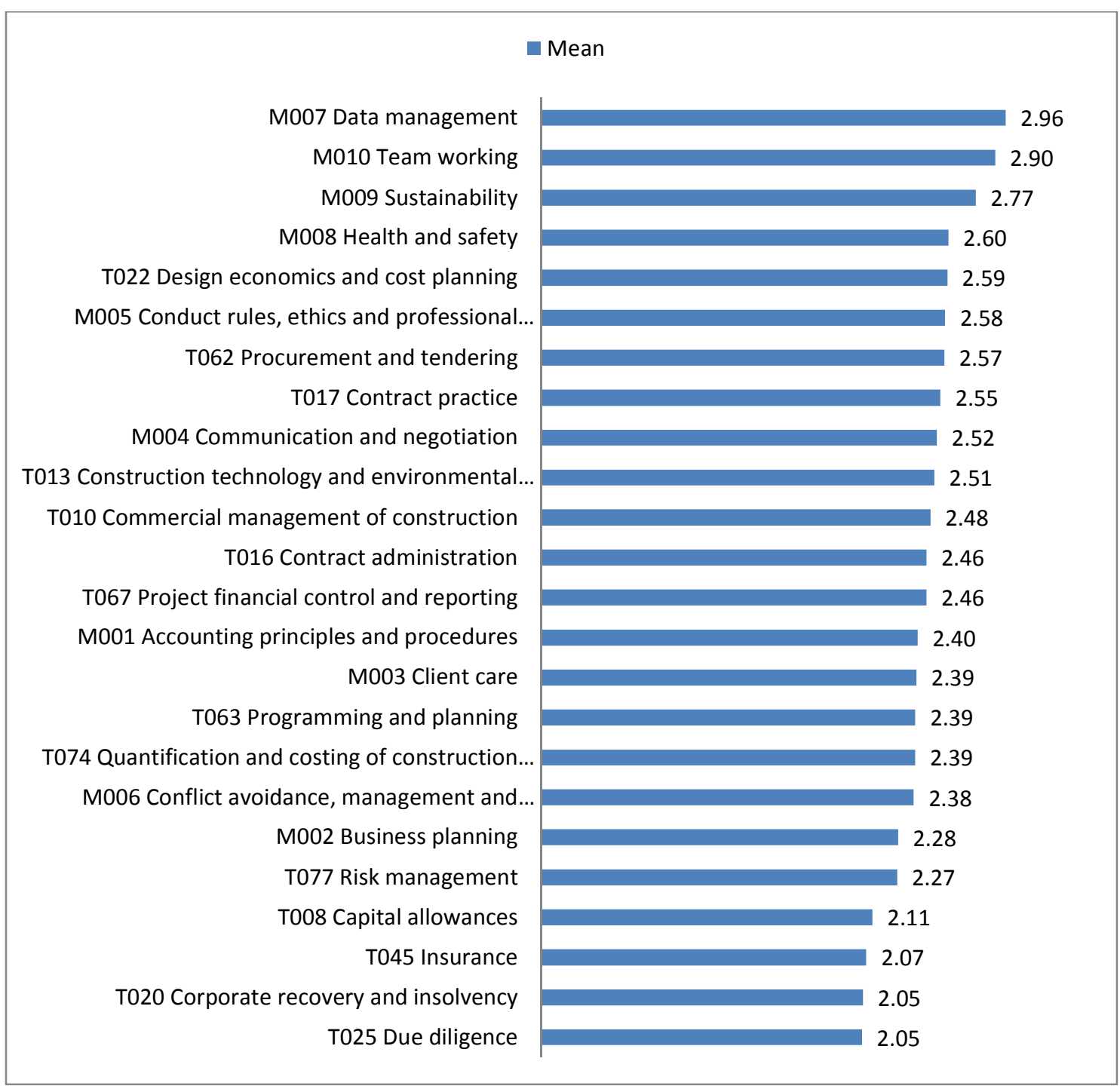

Figure 11: Industry's perception of achievement of competencies by QS graduates 


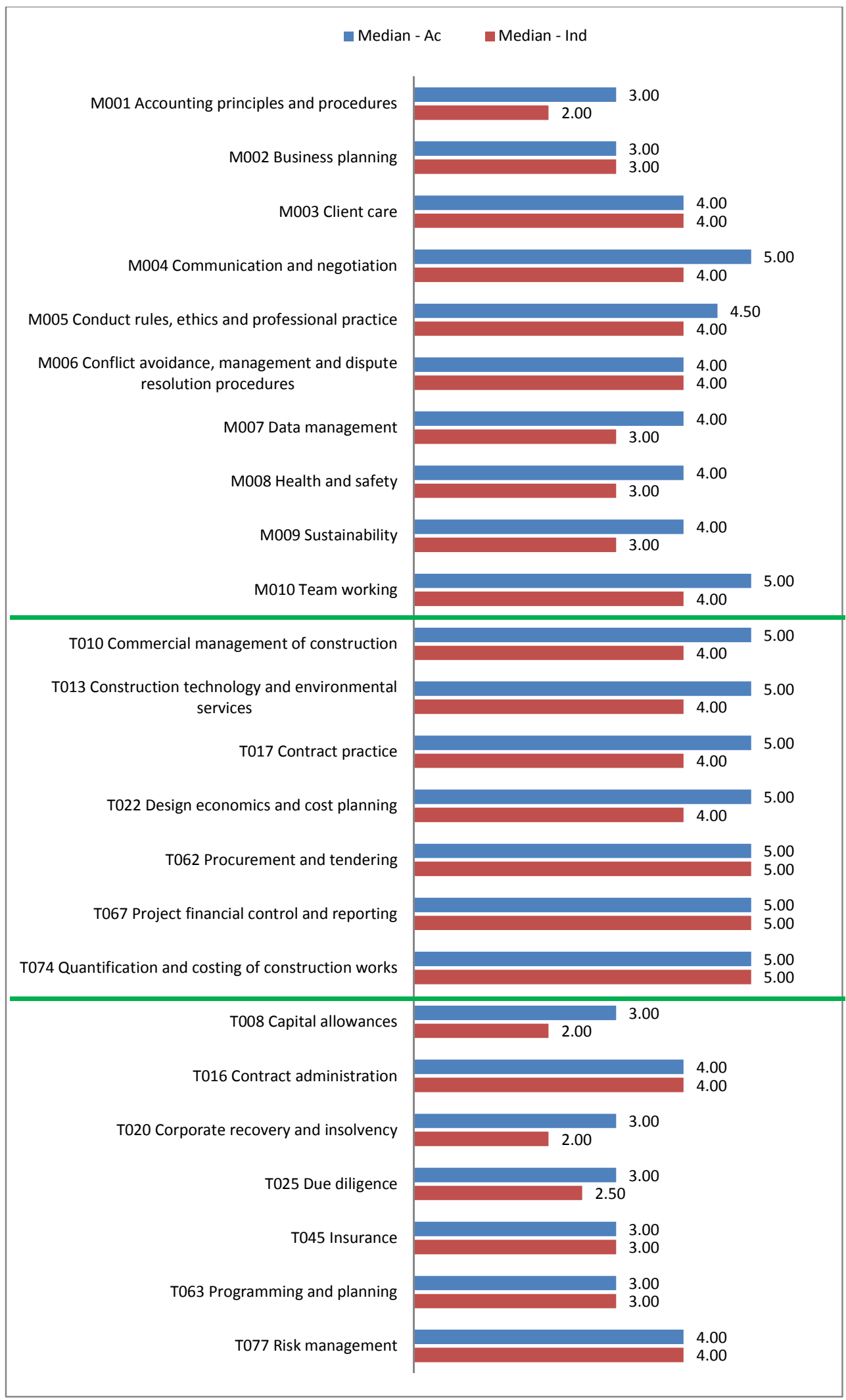

Figure 12: Ranking of competencies in the order of perceived importance 


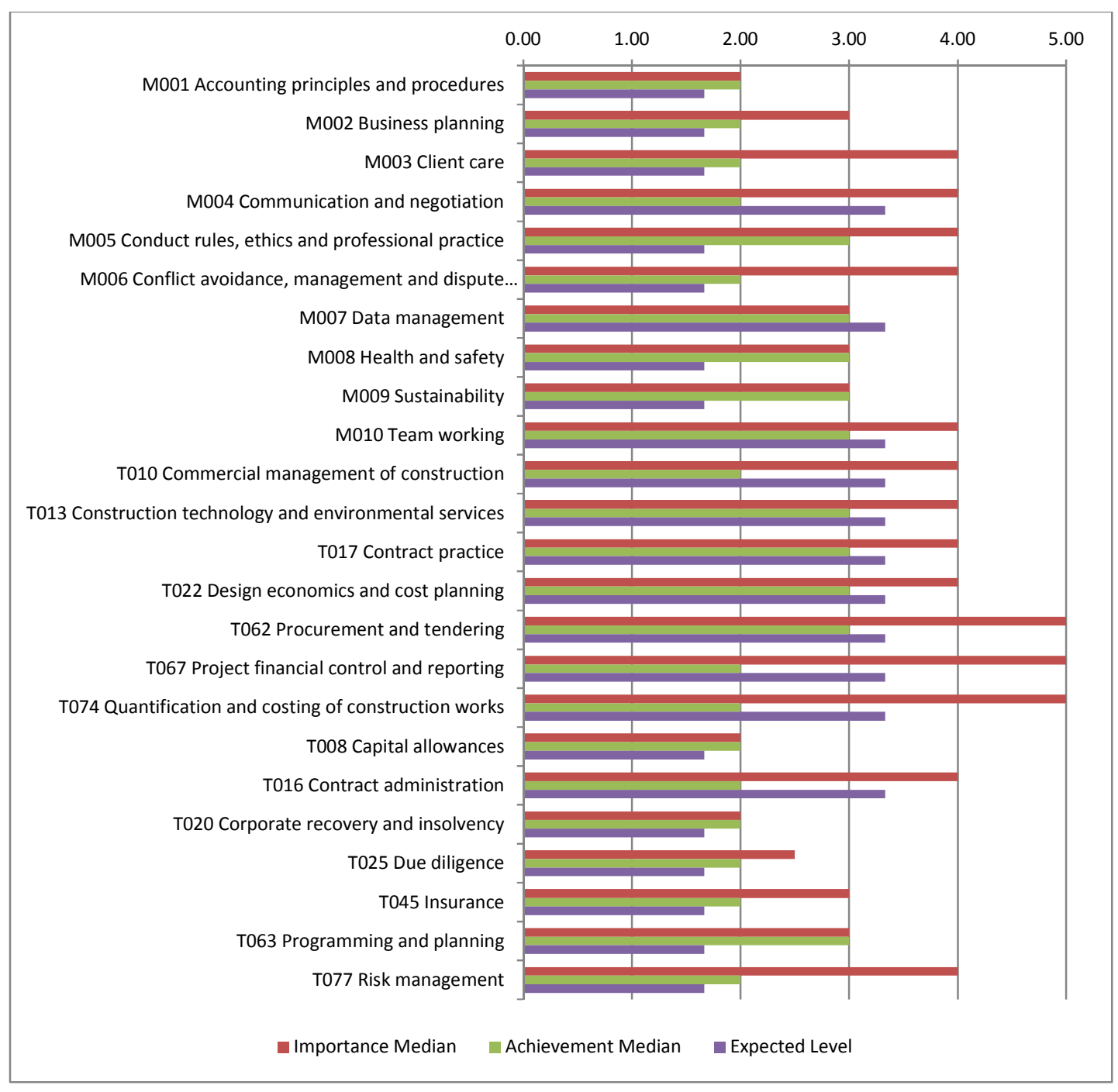

Figure 13: Cross comparison of competency expected level, importance ranking and graduate achievement 


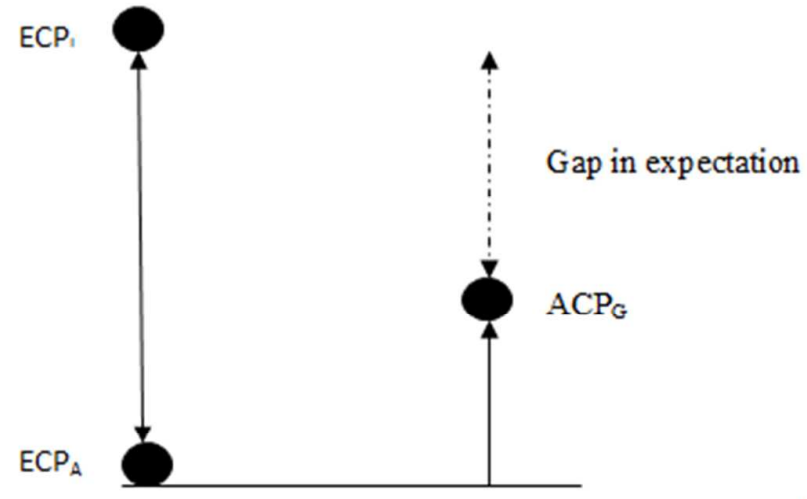

Figure 14: Perception gap in graduate competency

Key

ECP-Ex pected Com petency Profile ACP-Actual Com petency Profile

I-Industry

A-Aca demia

G-Graduate

..... Perception Gap 


\section{List of Tables}

Table 1: Summary of expected levels for mandatory competencies

\begin{tabular}{|c|c|c|c|c|c|c|c|}
\hline \multirow[b]{2}{*}{ Mandatory Competencies } & \multicolumn{3}{|c|}{ Academic } & \multicolumn{3}{|c|}{ Industry } & \multirow{2}{*}{$\begin{array}{l}\text { Level } \\
\text { Recommended }\end{array}$} \\
\hline & Level 1 & Level 2 & Level 3 & Level 1 & Level 2 & Level 3 & \\
\hline $\begin{array}{l}\text { M001 Accounting principles and } \\
\text { procedures }\end{array}$ & $62.22 \%$ & $33.33 \%$ & $4.44 \%$ & $79.40 \%$ & $18.60 \%$ & $2.00 \%$ & 1 \\
\hline M002 Business planning & $68.89 \%$ & $22.22 \%$ & $8.89 \%$ & $85.00 \%$ & $13.00 \%$ & $2.00 \%$ & 1 \\
\hline M003 Client care & $51.11 \%$ & $35.56 \%$ & $13.33 \%$ & $51.80 \%$ & $39.90 \%$ & $8.30 \%$ & 1 \\
\hline $\begin{array}{l}\text { M004 Communication and } \\
\text { negotiation }\end{array}$ & $11.11 \%$ & $73.33 \%$ & $15.56 \%$ & $26.90 \%$ & $56.80 \%$ & $16.30 \%$ & 2 (part) \\
\hline $\begin{array}{l}\text { M005 Conduct rules, ethics and } \\
\text { professional practice }\end{array}$ & $28.89 \%$ & $48.89 \%$ & $22.22 \%$ & $41.90 \%$ & $37.20 \%$ & $20.90 \%$ & 1 \\
\hline $\begin{array}{l}\text { M006 Conflict avoidance, } \\
\text { management and dispute } \\
\text { resolution procedures }\end{array}$ & $42.22 \%$ & $46.67 \%$ & $11.11 \%$ & $60.80 \%$ & $32.20 \%$ & $7.00 \%$ & 1 \\
\hline M007 Data management & $31.11 \%$ & $51.11 \%$ & $17.78 \%$ & $36.20 \%$ & $51.20 \%$ & $12.60 \%$ & 2 (part) \\
\hline M008 Health and safety & $33.33 \%$ & $51.11 \%$ & $15.56 \%$ & $49.50 \%$ & $41.20 \%$ & $9.30 \%$ & 1 \\
\hline M009 Sustainability & $31.11 \%$ & $53.33 \%$ & $15.56 \%$ & $64.50 \%$ & $30.20 \%$ & $5.30 \%$ & 1 \\
\hline M010 Team working & $13.33 \%$ & $48.89 \%$ & $37.78 \%$ & $21.60 \%$ & $60.50 \%$ & $17.90 \%$ & 2 (part) \\
\hline Percentage rank & $37.33 \%$ & $46.44 \%$ & $16.22 \%$ & $51.76 \%$ & $38.08 \%$ & $10.16 \%$ & \\
\hline
\end{tabular}

Table 2: Summary of expected levels for core competencies

\begin{tabular}{|c|c|c|c|c|c|c|c|}
\hline \multirow[b]{2}{*}{ Core Competencies } & \multicolumn{3}{|c|}{ Academic } & \multicolumn{3}{|c|}{ Industry } & \multirow{2}{*}{$\begin{array}{l}\text { Level } \\
\text { Recommended }\end{array}$} \\
\hline & Level 1 & Level 2 & Level 3 & Level 1 & Level 2 & Level 3 & \\
\hline $\begin{array}{l}\text { T010 Commercial management of } \\
\text { construction }\end{array}$ & $17.78 \%$ & $48.89 \%$ & $33.33 \%$ & $32.60 \%$ & $5.20 \%$ & $22.30 \%$ & 2 (part) \\
\hline $\begin{array}{l}\text { T013 Construction technology and } \\
\text { environmental services }\end{array}$ & $22.22 \%$ & $51.11 \%$ & $26.67 \%$ & $25.60 \%$ & $53.20 \%$ & $21.30 \%$ & 2 (part) \\
\hline T017 Contract practice & $17.78 \%$ & $53.33 \%$ & $28.89 \%$ & $24.60 \%$ & $50.50 \%$ & $24.90 \%$ & 2 (part) \\
\hline $\begin{array}{l}\text { T022 Design economics and cost } \\
\text { planning }\end{array}$ & $13.33 \%$ & $44.44 \%$ & $42.22 \%$ & $27.90 \%$ & $50.80 \%$ & $21.30 \%$ & 2 (part) \\
\hline T062 Procurement and tendering & $11.11 \%$ & $46.67 \%$ & $42.22 \%$ & $20.90 \%$ & $50.20 \%$ & $28.90 \%$ & 2 (part) \\
\hline $\begin{array}{l}\text { T067 Project financial control and } \\
\text { reporting } \\
\text { T074 Ountification and costing }\end{array}$ & $11.11 \%$ & $53.33 \%$ & $35.56 \%$ & $21.30 \%$ & $46.50 \%$ & $32.20 \%$ & 2 (part) \\
\hline of construction works & $11.11 \%$ & $46.67 \%$ & $42.22 \%$ & $12.60 \%$ & $50.50 \%$ & $36.90 \%$ & 2 (part) \\
\hline Percentage rank & $14.92 \%$ & $49.21 \%$ & $35.87 \%$ & $23.64 \%$ & $49.56 \%$ & $26.83 \%$ & \\
\hline
\end{tabular}

Table 3: Summary of expected levels for optional competencies

\begin{tabular}{|c|c|c|c|c|c|c|c|}
\hline \multirow[b]{2}{*}{ Optional Competencies } & \multicolumn{3}{|c|}{ Academic } & \multicolumn{3}{|c|}{ Industry } & \multirow{2}{*}{$\begin{array}{l}\text { Level } \\
\text { Recommended }\end{array}$} \\
\hline & Level 1 & Level 2 & Level 3 & Level 1 & Level 2 & Level 3 & \\
\hline T008 Capital allowances & $66.67 \%$ & $26.67 \%$ & $6.67 \%$ & $85.70 \%$ & $13.30 \%$ & $1.00 \%$ & 1 \\
\hline T016 Contract administration & $22.22 \%$ & $55.56 \%$ & $22.22 \%$ & $30.90 \%$ & $50.80 \%$ & $18.30 \%$ & 2 (part) \\
\hline $\begin{array}{l}\text { T020 Corporate recovery and } \\
\text { insolvency } \\
\text { T025 Due diligence }\end{array}$ & $\begin{array}{l}80.00 \% \\
68.89 \%\end{array}$ & $\begin{array}{l}13.33 \% \\
26.67 \%\end{array}$ & $\begin{array}{l}6.67 \% \\
4.44 \%\end{array}$ & $\begin{array}{l}91.70 \% \\
83.40 \%\end{array}$ & $\begin{array}{l}7.30 \% \\
13.60 \%\end{array}$ & $\begin{array}{l}1.00 \% \\
3.00 \%\end{array}$ & $\begin{array}{l}1 \\
1\end{array}$ \\
\hline T045 Insurance & $60.00 \%$ & $33.33 \%$ & $6.67 \%$ & $76.70 \%$ & $19.90 \%$ & $3.30 \%$ & 1 \\
\hline T063 Programming and planning & $40.00 \%$ & $48.89 \%$ & $11.11 \%$ & $60.80 \%$ & $34.20 \%$ & $5.00 \%$ & 1 or 2 (part) \\
\hline T077 Risk management & $28.89 \%$ & $51.11 \%$ & $20.00 \%$ & $59.50 \%$ & $33.60 \%$ & $7.00 \%$ & 1 or 2 (part) \\
\hline Percentage rank & $52.38 \%$ & $36.51 \%$ & $11.11 \%$ & $69.81 \%$ & $24.67 \%$ & $5.51 \%$ & \\
\hline
\end{tabular}

